\title{
Cyclic Stress Response and Fracture Behaviors of Alloy 617 Base Metal and Weld Joints under LCF Loading
}

\author{
Seon Jin Kim, ${ }^{1}$ Rando Tungga Dewa, ${ }^{1}$ Woo Gon Kim, ${ }^{2}$ and Min Hwan Kim ${ }^{2}$ \\ ${ }^{1}$ Pukyong National University, 365 Shinsunro, Nam-gu, Busan 608-739, Republic of Korea \\ ${ }^{2}$ Korea Atomic Energy Research Institute, 989-111 Daedeokdaero, Yuseong-gu, Daejeon 305-353, Republic of Korea \\ Correspondence should be addressed to Seon Jin Kim; sjkim@pknu.ac.kr
}

Received 4 June 2015; Accepted 31 August 2015

Academic Editor: Kaushik Das

Copyright (c) 2015 Seon Jin Kim et al. This is an open access article distributed under the Creative Commons Attribution License, which permits unrestricted use, distribution, and reproduction in any medium, provided the original work is properly cited.

\begin{abstract}
Cyclic stress response and fracture behaviors of Alloy 617 base metal (BM) and Alloy 617 weld joints (WJ) are investigated under strain controlled low cycle fatigue (LCF) loading. Axial fully reversed total-strain controlled tests have been conducted at room temperature with total strain ranges of $0.6,0.9,1.2$, and $1.5 \%$. At the all testing conditions, weld joint specimens have shown higher peak stresses than the base metal specimens, whereas the plastic strain accumulation of the base metal specimens is comparatively higher than those of the weld joint specimens. The cyclic stress response behavior of both base metal and weld joint specimens revealed initial cyclic hardening during first small number of cycles followed by progressive softening to failure. Higher strain amplitudes decreased the fatigue lives for both base metal and weld joint specimens; subsequently weld joint specimens had lower fatigue resistances relative to base metal specimens. Furthermore, the cracking in weld joint specimens initiated in the weld metal (WM) region. The crack initiation and propagation showed transgranular mode for both base metal and weld joint specimens; especially weld joint specimens showed a wedge type crack initiation about 45 degrees to the loading direction because of the dendritic structure.
\end{abstract}

\section{Introduction}

The very high temperature gas-cooled reactor (VHTR) is currently the most promising reactor among the Generation4 reactors for producing electricity and hydrogen economically. The VHTR structural components like the reactor internals, piping, hot gas ducts (HGD), and intermediate heat exchangers (IHX) are designed for a design life of $30-60$ years at $950^{\circ} \mathrm{C}$ and $3-8 \mathrm{MPa}$ in He impurities. The HGD and IHX are key components, and their materials have potential for use in nickel-based superalloys such as Alloy 617, Haynes 230, Hastelloy-X, and Alloy $800 \mathrm{H}$. The Alloy 617 does have the distinction of possessing very high creep resistance at elevated temperatures when compared with other nickel based alloys. In addition to its high temperature strength, it also has excellent resistance to wide range of corrosive environments and is readily formed and welded by conventional techniques. For this reasons, Alloy 617 is considered as one of the leading candidates because of its highest allowable design stress compared to other superalloys for construction of the IHX associated with the reformer system [1-4].

The LCF loadings are suspected to a result of power transients and temperature gradient induced thermal strain during operation as well as startups and shutdowns and also the fluctuated work load, each of which produces cyclic loading $[2,5]$. LCF situation is characterized by high plastic strain in low frequency and the fatigue life is about $<10^{4}$ cycles. Although the low cycle fatigue behavior of Alloy 617 base metal has been studied by many researchers [5-9], less information is available on the welded joints [10]. Extensive high temperature low cycle fatigue studies of welded joints in Alloy 617 and austenitic stainless steels have shown markedly lower lives in weld areas $[10,11]$. In mechanical structures, the welded components are unavoidable and some of the components were joined by various welding techniques. Moreover, the welded joints are more brittle than the base metal and may have several original defects [1]. In addition, the welded joints are microstructurally and mechanically heterogeneous, which could form one of the potential sites 
TABLE 1: The chemical composition of Alloy 617 plate used in this study (wt.\%).

\begin{tabular}{cccccccccccccccc}
\hline & & $\mathrm{C}$ & $\mathrm{Ni}$ & $\mathrm{Fe}$ & $\mathrm{Si}$ & $\mathrm{Mn}$ & $\mathrm{Co}$ & $\mathrm{Cr}$ & $\mathrm{Ti}$ & $\mathrm{P}$ & $\mathrm{S}$ & $\mathrm{Mo}$ & $\mathrm{Al}$ & $\mathrm{B}$ & $\mathrm{Cu}$ \\
\hline ASTM & Min & 0.05 & $\mathrm{Bal}$ & $\ldots$ & $\ldots$ & $\ldots$ & 10.0 & 20.0 & $\ldots$ & $\ldots$ & $\ldots$ & 8.0 & 0.8 & $\ldots$ & $\ldots$ \\
Spec. & Max & 0.15 & Bal. & 3.0 & 0.5 & 0.5 & 15.0 & 24.0 & 0.6 & 0.015 & 0.015 & 10.0 & 1.5 & 0.006 & 0.5 \\
\multicolumn{1}{l}{ Alloy 617} & 0.08 & 53.11 & 0.949 & 0.084 & 0.029 & 12.3 & 22.2 & 0.4 & 0.003 & $<0.002$ & 9.5 & 1.06 & $<0.002$ & 0.0268 \\
\hline
\end{tabular}

of the fatigue failure. The welded section material could be considerably affected by the welding process which is responsible for heterogeneities. Therefore, the fatigue damage evolution mechanisms such as fatigue crack initiation and crack propagation could be different and the evaluation of fatigue damage of welded joints must be confirmed [11].

Current research activities at Korea Atomic Energy Research Institute (KAERI) and Pukyong National University (PKNU) focus on the study of low cycle fatigue behavior of Alloy 617 base metal and the welded joint specimens were machined from GTAW butt-welded with temperature between passes under $177^{\circ} \mathrm{C}$ and the postheat-treatment was not conducted because the Ni-based superalloy was not normally applied. After welding, the soundness of the weldments was investigated by ultrasonic, tensile, and bending tests. In the present paper, in order to understand the baseline of high temperature low cycle fatigue behavior for Alloy 617 welded joints, initial strain-controlled low cycle fatigue testing was performed in air at room temperature with a constant strain ratio $(R=-1)$, as listed in ASTM Standard number E60692 [12]. This paper focuses on the comparative investigation on cyclic stress response and fracture behaviors of Alloy 617 base metal and Alloy 617 welded joints under LCF loading. The cyclic stress response behaviors have been investigated at room temperature condition in air with four different total strain ranges of $0.6,0.9,1.2$, and $1.5 \%$. And also, to clearly compare the low cycle fatigue fracture modes of Alloy 617 base metal and the welded joint specimens, the microscopic investigations were examined for selected specimens.

\section{Experimental Procedures}

2.1. Materials and Specimens. The chemical composition of the Alloy 617 (UNS 06617) used in this study is given in Table 1. The amount of each element was well within the ASTM Standard B 168-08 specifications [13]. Base metal specimens were machined from $25 \mathrm{~mm}$ thick rolled plate and the weld joint specimens were machined from gas tungsten arc welding (GTAW) butt-welded plate such that the loading direction was oriented transverse to the welding direction. Fatigue specimens especially for weld joint, used for this experiment, were machined and located in the upper side of weld pad as seen in Figure 1(a). Figure 1(b) shows the cylindrical specimen's shape and dimensions of LCF specimens with $6.0 \mathrm{~mm}$ of diameter in the reduced section with a parallel length of $18 \mathrm{~mm}$ and a gauge length of $12.5 \mathrm{~mm}$. The cross weld specimens that were machined from the weld pad have a reduced section contained BM, Heat Affected Zone (HAZ), and WM with the optical microstructures which have been shown in Figure 2, respectively. The welded specimens were prepared which have a single $\mathrm{V}$-groove of $80^{\circ}$ of an angle and joined from the GTAW process. Hence, a filler metal was used for KW-T617 (brand name). It was prepared according the AWS specifications, AWS A 5.14-05 ERNiCrMo-1 (UNS N06617), and the diameter was $2.4 \mathrm{~mm}$. After welding process, the soundness of the weldments was evaluated by ultrasonic, tensile, and bending tests. The details of the welding procedure are shown in [1].

2.2. Low Cycle Fatigue Test Procedures. Fully reversed $(R=$ -1) total axial strain-controlled LCF tests were conducted at four different total strain ranges of $1.5,1.2,0.9$, and $0.6 \%$ at room temperature on Alloy 617 base metal (BM) and Alloy 617 welded joints (WJ) in air by using a servohydraulic machine (Instron 8516 capacity $100 \mathrm{kN}$ ) equipped at a constant frequency of $0.25 \mathrm{~Hz}$. Consequently, the strain rate was varied between $3 \cdot 10^{-3} \mathrm{~s}^{-1}$ and $7.5 \cdot 10^{-3} \mathrm{~s}^{-1}$ depending on total strain range. According to $[7,10,14]$, fatigue life could be defined to a $20-30 \%$ drop in the maximum tensile stress measured at half-life, when the tests were terminated based upon $100 \%$ peak load drop of the stable value or complete fracture. The fatigue life is not very sensitive to the exact value of load drop used to define failure because of the rapidly falling peak stress during the final crack propagation phase. A triangular strain-time wave form was employed for all tests. In the all tests, the push-pull mode ramp rates are equal. A closed loop servohydraulic testing system equipped with a high precision extensometer with $12.5 \mathrm{~mm}$ gage length was attached to the gauge section for carefully monitoring and recording the real time data of stress and strain in detail. Furthermore, the fatigue crack initiation and propagation mechanisms were investigated to discover the fracture mode and the failure mechanism of this material for selected specimens by using optical microscopy (OM) and scanning electron microscopy (SEM). The specimens for OM observations were prepared by cutting into two parts which then mounted and polished the cut surface. Afterward, the specimens were etched in a solution containing hydrochloric acid, ethanol, and copper II chloride.

\section{Results and Discussion}

3.1. Tensile Properties and Cyclic Stress Response Behavior. The tensile tests have been first done as a reference data for Alloy 617 BM and Alloy 617 WJ. The tensile test specimens were machined into a rectangular cross section with a gage length of $28.5 \mathrm{~mm}$, width of $6.25 \mathrm{~mm}$, and thickness of $1.5 \mathrm{~mm}$. Further details of the tensile test preparation can be found in [1]. Figure 3 shows the stress-strain curves for BM and weldment specimens. The unique tensile properties were observed from each specimens. Table 2 shows the results of the tensile property measurements at RT condition. However, the WJ 


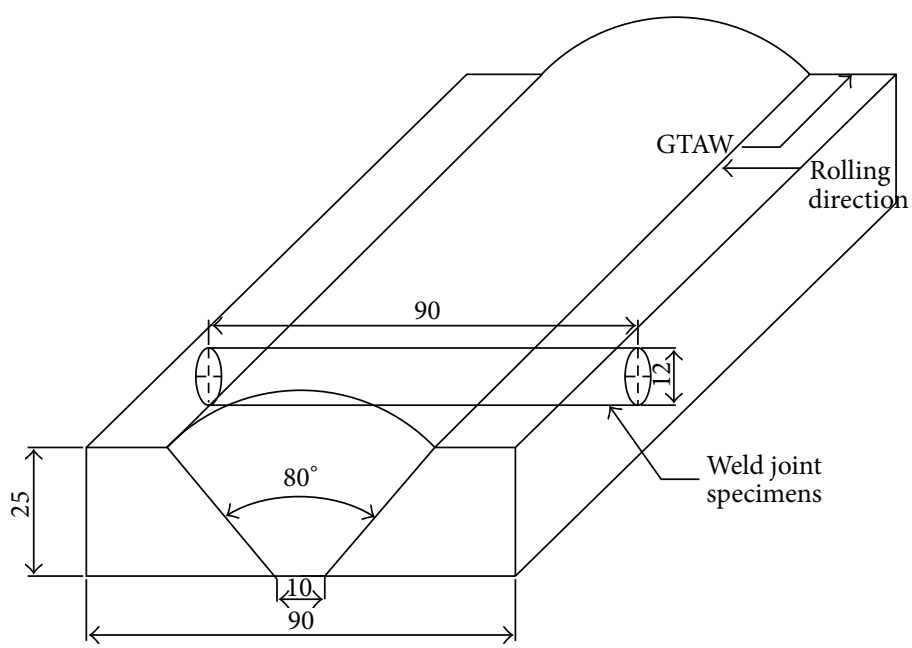

(a)

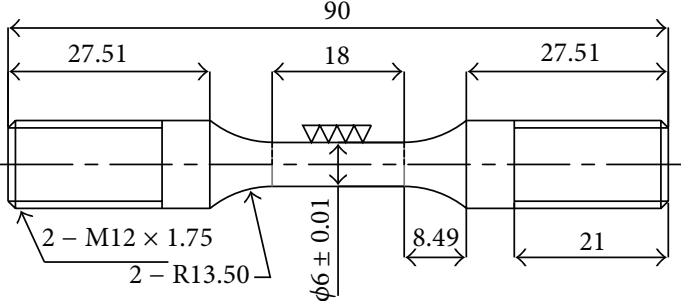

(b)

Figure 1: (a) The weld pad configuration for WJ specimen. (b) The cylindrical specimen's shape and dimension for Alloy 617 BM and Alloy $617 \mathrm{WJ}$.

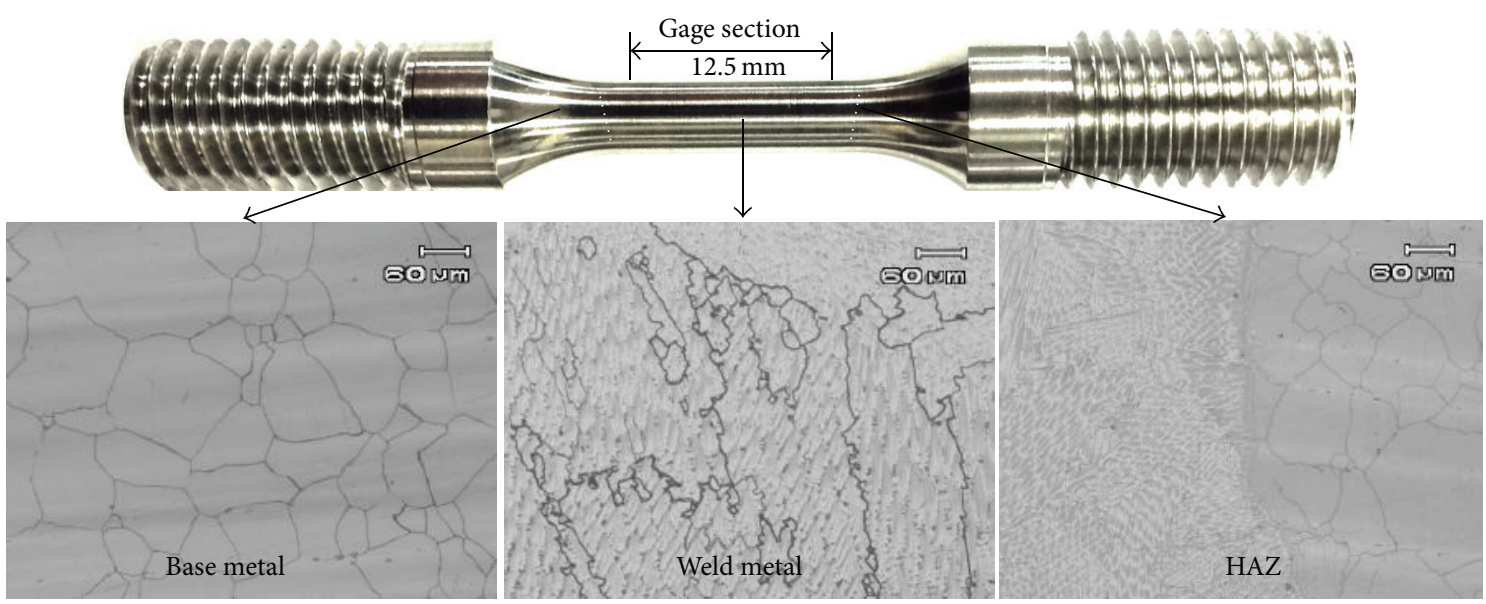

FIGURE 2: Microstructures with respect to LCF welded specimen.

specimen showed a higher $0.2 \%$ yield stress (YS) value than that of the BM at RT operation. It is notable that the ultimate tensile strength (UTS) values of the BM were comparatively higher than the WJ. Therefore, the BM ductility from the tensile elongation increased significantly compared with that of the WJ.

For strain-controlled tests, a material's cyclic stress response behavior can be characterized by examining its stress response as a function of cycle number. Generally, a material's initial response during LCF is to harden through a small number of cycles and then reach a period of either cyclic saturation or cyclic softening, depending on the microstructure and temperature and total strain range [15]. Comparison of peak and valley stresses response curves at total strain range conditions of (a) $0.6 \%$ and (b) $1.5 \%$ as a function of number of cycles to failure is illustrated in Figure 4 under continuous cyclic loading condition. The cyclic stress response was almost symmetrical in tension and compression.
As shown in Figure 4, the WJs exhibit a higher cyclic stress response compared with that of the BMs, because of the harder zone in WJ. It is believed that higher stress range caused a short life in WJs. And also, the stress amplitude response curves at four total strain ranges as a function of number of cycles to failure are illustrated in Figure 5 under continuous cyclic loading. The cyclic stress response for both $\mathrm{BM}$ and WJ exhibited a cyclic softening regime for the major portion of the life after a brief period of initial hardening. The short period of cyclic initial hardening was observed about 2-200 cycles for both BM and WJ specimens and remained softening phase until failure. At the lower strain range $(0.6 \%)$, the saturation regime was also visible. The similar cyclic stress response behavior was exhibited for both $\mathrm{BM}$ and WJ specimens. However, the WJ specimens showed a slow degradation in stress amplitude response compared to the BM specimens. About the end of the tests, the stress amplitude decreased rapidly, indicating the formation of microcracks and their subsequent growth [16]. In order to 
TABLE 2: The tensile mechanical properties of Alloy 617.

\begin{tabular}{lccccc}
\hline Temp. $\left({ }^{\circ} \mathrm{C}\right)$ & Base metal & \multicolumn{3}{c}{ Weld joint (GTAW) } \\
UTS (MPa) & YS (MPa) & EL (\%) \\
\hline RT & 346.6 & 811.1 & 59.9 & 462 & 764.9 \\
\hline
\end{tabular}

TABLE 3: The experimental results of LCF for Alloy 617 BM and Alloy 617 WJ.

\begin{tabular}{lccccccccccc}
\hline Specimen reference & $N_{f}$ & $\begin{array}{c}\Delta \varepsilon_{T} \\
(\%)\end{array}$ & $\begin{array}{c}\Delta \varepsilon_{e} / 2 \\
(\%)\end{array}$ & $\begin{array}{c}\Delta \varepsilon_{p} / 2 \\
(\%)\end{array}$ & $\begin{array}{c}\Delta \sigma / 2 \\
(\mathrm{MPa})\end{array}$ & $\begin{array}{c}\text { Specimen } \\
\text { reference }\end{array}$ & $N_{f}$ & $\begin{array}{c}\Delta \varepsilon_{T} \\
(\%)\end{array}$ & $\begin{array}{c}\Delta \varepsilon_{e} / 2 \\
(\%)\end{array}$ & $\begin{array}{c}\Delta \varepsilon_{p} / 2 \\
(\%)\end{array}$ & $\begin{array}{c}\Delta \sigma / 2 \\
(\mathrm{MPa})\end{array}$ \\
\hline BM-RT150 & 1409 & 1.5 & 0.315 & 0.435 & 583.037 & WJ-RT150 & 416 & 1.5 & 0.367 & 0.383 & 665.854 \\
BM-RT120 & 3410 & 1.2 & 0.279 & 0.321 & 552.406 & WJ-RT120 & 1485 & 1.2 & 0.326 & 0.274 & 656.179 \\
BM-RT090 & 13042 & 0.9 & 0.245 & 0.205 & 505.539 & WJ-RT090 & 2924 & 0.9 & 0.293 & 0.157 & 621.123 \\
BM-RT060 & 42360 & 0.6 & 0.222 & 0.078 & 474.208 & WJ-RT060 & 28422 & 0.6 & 0.273 & 0.027 & 545.578 \\
\hline
\end{tabular}

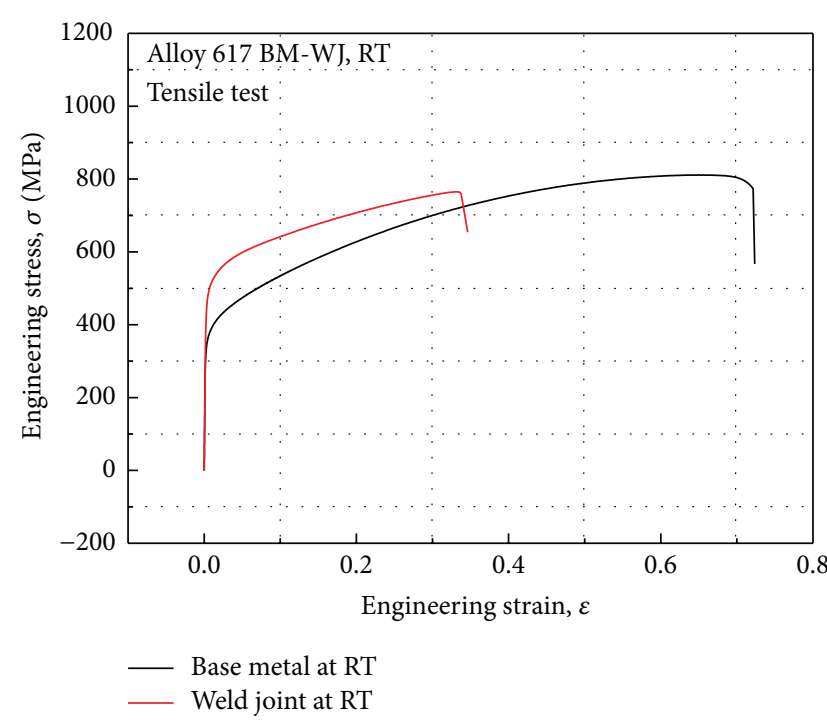

FIGURE 3: Stress-strain curves for Alloy $617 \mathrm{BM}$ and Alloy $617 \mathrm{WJ}$ in tensile tests at RT condition with a strain rate of $5.85 \times 10^{-4} 1 / \mathrm{s}$.

clearly investigate the effects of initial cyclic hardening for BM and WJ specimens, the cyclic hardening factor is considered. The cyclic hardening factor can be calculated as follows [17]:

$$
H_{s}=\frac{\left(\sigma_{a}\right)^{p}-\left(\sigma_{a}\right)^{1}}{\left(\sigma_{a}\right)^{1}} \times 100 \%,
$$

where $\sigma_{a}{ }^{p}$ is the stable stress amplitude and $\sigma_{a}{ }^{1}$ is the stress amplitude at the first cycle. The dependence of cyclic hardening on total strain range is shown in Figure 6. The degree of cyclic strain hardening for BM specimens increased linearly with total strain range. However, Alloy 617 WJ specimens in this work increased to $1.2 \%$ total strain range and slightly decreased at $1.5 \%$ of total strain range. The BM specimens showed relatively higher value of $H_{s}$ compared to WJ specimens at all total strain ranges.

In order to further investigate the nature of cyclic stress response for $\mathrm{BM}$ and $\mathrm{WJ}$ specimens, the stable hysteresis loops were evaluated and investigated at half-life period of fatigue life. Figure 7 shows the shape of the hysteresis loops for (a) Alloy $617 \mathrm{BM}$ and (b) Alloy $617 \mathrm{WJ}$ specimens in each total strain range at room temperature. The stable loop remains unchanged until the crack initiation occurs. At the half-life cycle, the hysteresis loops were all asymmetric at both BM and WJ specimens, where the peak stresses of WJ specimen at each total strain range were greater than the $\mathrm{BM}$. The shape shows significant dependence on the material property (namely, BM and $\mathrm{WJ}$ ) and total strain range, normally short and fat for the BM, while the WJ shows long and narrow hysteresis loop. The presented hysteresis loops showed that the total stress range increases with increasing total strain range, as known monotonic strain hardening behavior [15].

3.2. Fatigue Life Evaluation. From the viewpoint of engineering applications, the best way to describe the low cycle fatigue behavior is to use the fatigue life of the alloy as a function of total strain ranges at the BM and WJ, shown in Table 3. It was found that the material properties had a significant influence on the LCF life. The LCF fatigue resistance of the $\mathrm{BM}$ is higher than the WJ due to mechanical aspect as well as fine grain size and slip band grain boundary interaction at all the testing conditions. It should be pointed out that the total strain range governs the stress level in this investigation. The fatigue life-strain relationship under the total strain range controlled condition is often described using the CoffinManson equation, which is

$$
\frac{\Delta \varepsilon_{t}}{2}=\varepsilon_{f}^{\prime}\left(2 N_{f}\right)^{c}+\frac{\sigma_{f}^{\prime}}{E}\left(2 N_{f}\right)^{b},
$$

where $\Delta \varepsilon_{t} / 2$ is the total strain amplitude, $\Delta \varepsilon_{e} / 2$ is the elastic strain amplitude, $\Delta \varepsilon_{p} / 2$ is the plastic strain amplitude, and $2 N_{f}$ is the number of reversals to failure. $\sigma_{f}{ }^{\prime}$ is the fatigue strength coefficient, $b$ is the fatigue strength exponent, $\varepsilon_{f}{ }^{\prime}$ is the fatigue ductility coefficient, $c$ is the fatigue ductility exponent, and $E$ is the elastic modulus.

Figure 8 shows the Coffin-Manson equation plots for the $\mathrm{BM}$ and WJ specimens. Those data were analyzed using a least squares fit method, and the coefficients and exponents in the Coffin-Manson equation were determined and are listed in Table 4 . The material constants $K^{\prime}$ and $n^{\prime}$ are cyclic 


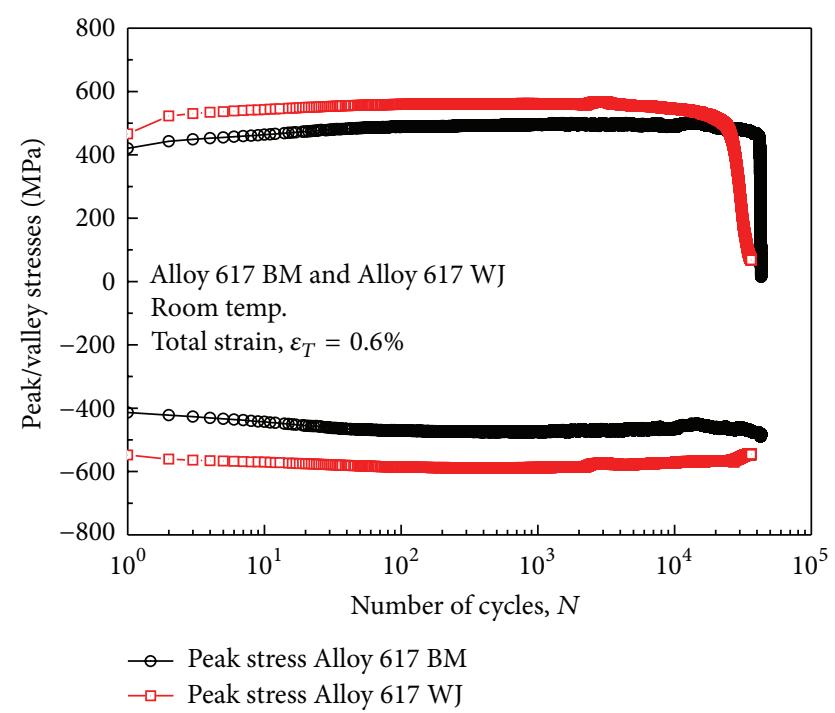

(a)

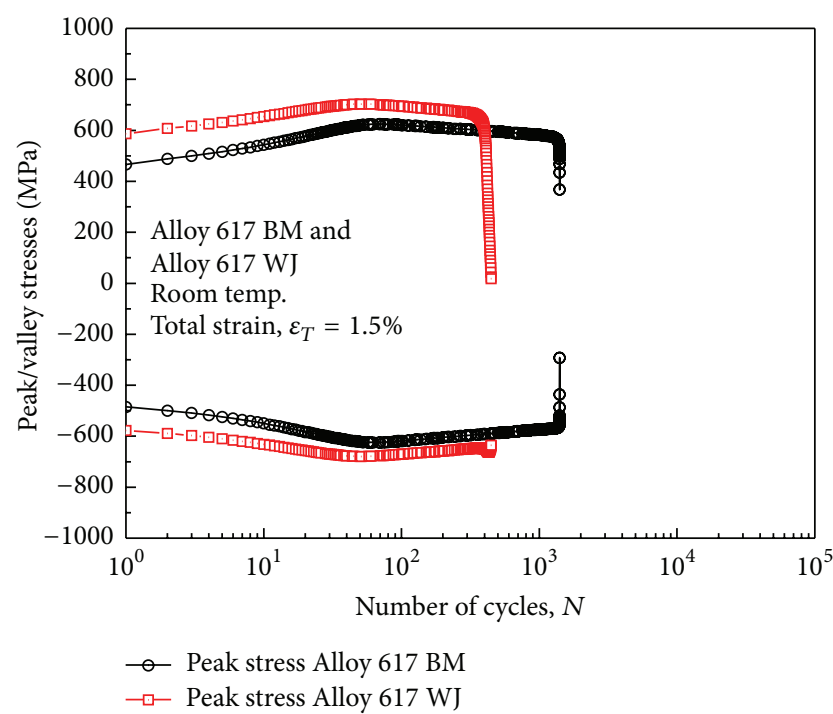

(b)

FIGURE 4: Peak/valley stresses versus number of cycles in LCF with total strain controlled of (a) $0.6 \%$ and (b) $1.5 \%$.

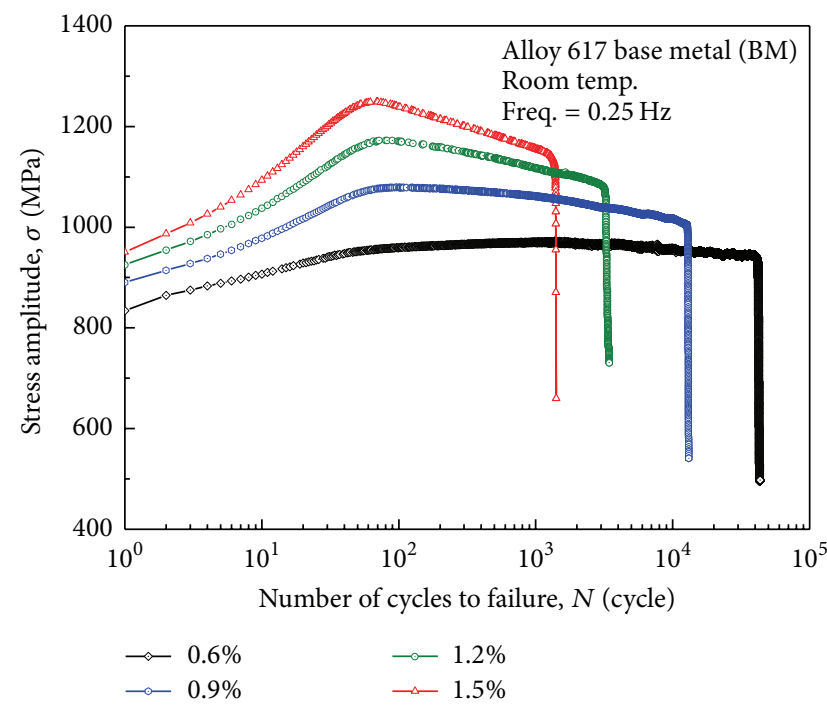

(a)

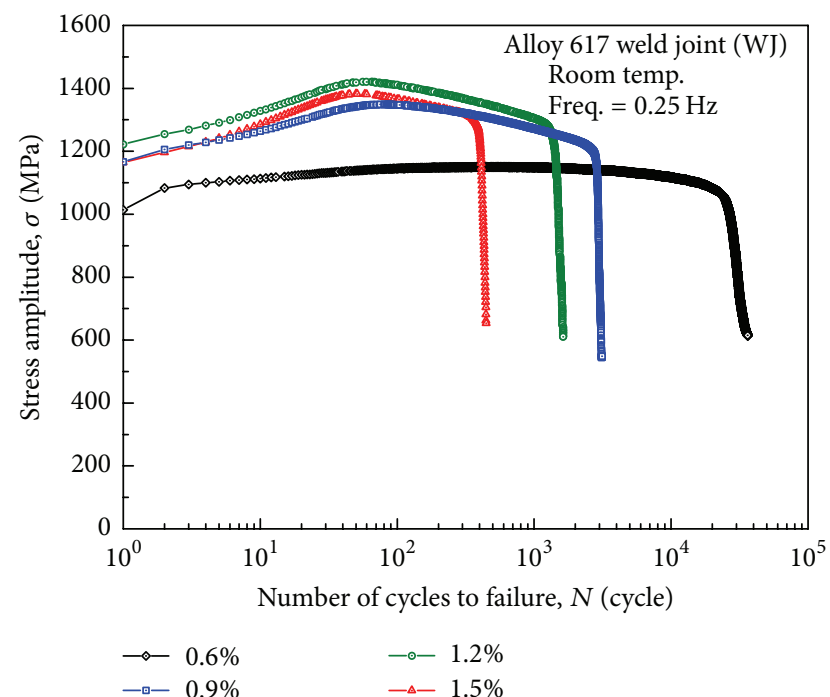

(b)

FIgURE 5: The stress amplitude as a function of number of cycles for (a) Alloy 617 BM and (b) Alloy 617 WJ.

strength coefficient and cyclic strain hardening exponent. Those values were obtained by fitting a power law relationship to the stress amplitude. The strain-life curves were simply fitted and related to (2). In both logarithmic coordinates, those that were plotted by two straight lines with slopes $b$ and $c$, the intercepts with the vertical axis of the two straight lines represent the constants $\sigma_{f}^{\prime} / E$ and $\varepsilon_{f}{ }^{\prime}$. It is obvious that the cyclic lives were found to be strong function of material property, namely, BM and WJ. At higher total strain ranges, the plastic strain tends to be higher than the elastic strain and plays a dominant role for dislocations. The fatigue resistance of WJ specimen is lower than that of BM specimen.

In Figure 8, although the alloys exhibit similar elastic fatigue life, the ductility of the BM is superior to that of the
WJ, which is responsible for their longer transition of fatigue life, $N_{t}$ [17]. From the regression parameters that are listed in Table 4, we can back substitute the values at any desired conditions to obtain the predicted lives. The LCF lives of the $\mathrm{BM}$ and $\mathrm{WJ}$ can be predicted by the Coffin-Manson equations and well coincided with the experimental data.

3.3. Fracture behavior of the $B M$ and $W J$. It is interesting to note that the fracture surface morphologies between the $\mathrm{BM}$ and WJ distinctly showed different crack mechanism. Figure 9 shows fractured specimens that illustrate failure occurring inside of the gauge section for BM and WJ. Cracks in BM specimen are flat-type related to the fatigue loading direction, whereas the WJ reveals relatively wedge-type 
TABLE 4: Coefficients and exponents for regression analysis of the BM and WJ.

\begin{tabular}{lccccccc}
\hline Specimen & $\varepsilon_{f}^{\prime}$ & $c$ & $\sigma_{f}^{\prime}(\mathrm{MPa})$ & $b$ & $\bar{E}(\mathrm{GPa})$ & $n^{\prime}$ \\
\hline BM-RT & 0.501 & -0.567 & 1519.55 & -0.104 & 214.4 & 0.118 \\
WJ-RT & 0.398 & -0.654 & 1213.04 & -0.069 & 214.4 & 0.076 \\
\hline
\end{tabular}

TABLE 5: The schematic diagrams of failure pattern for Alloy 617 BM and Alloy $617 \mathrm{WJ}$ tested at RT.

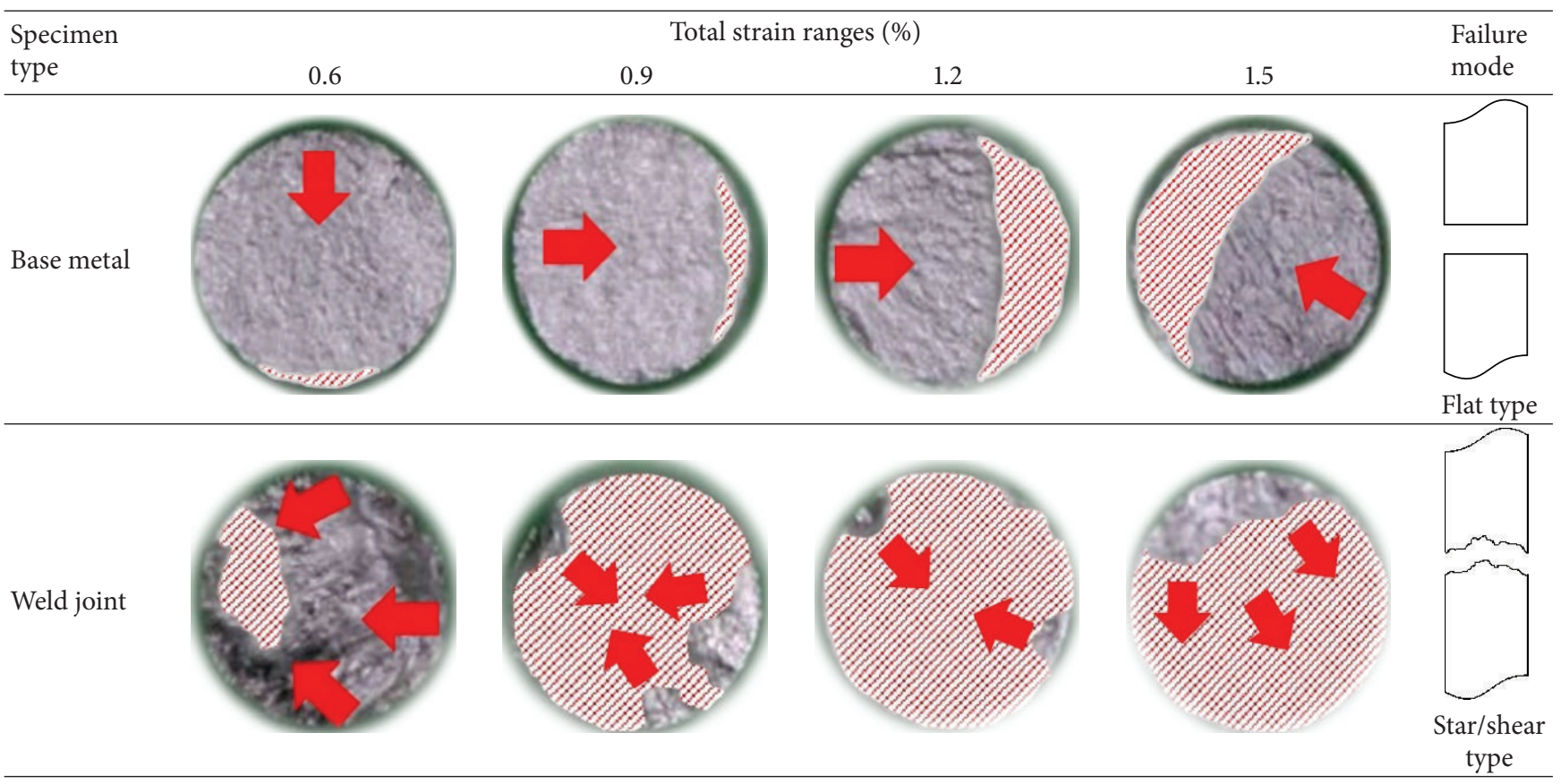

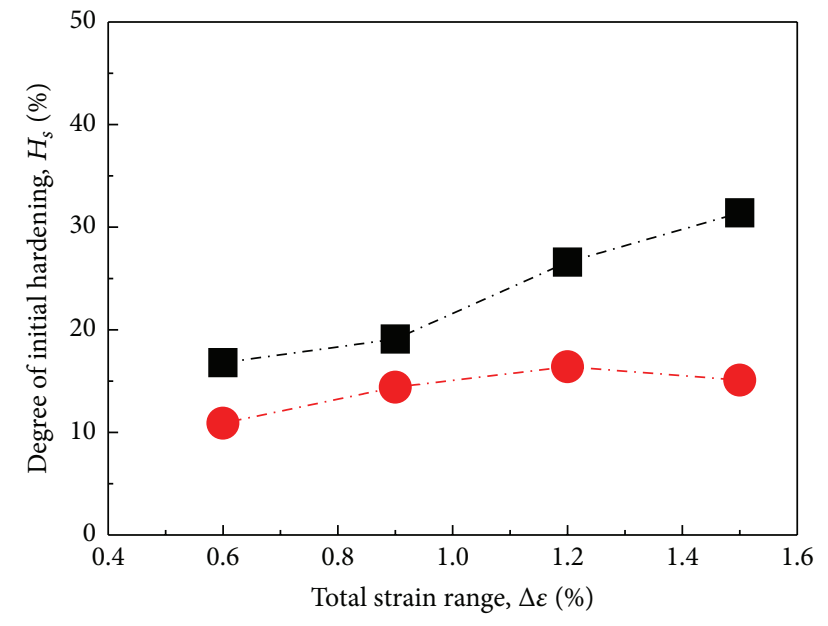

Degree of initial hardening, $H_{s_{f}}$ for $\mathrm{BM}$
. Degree of initial hardening, $H_{s_{f}}$ for WJ

FIGURE 6: The degree of cyclic hardening factor on total strain range in Alloy 617 BM and Alloy 617 WJ.

(star/shear shape), as shown in Figure 9. However, as total strain range levels increased, the fracture mode of the WJ progressively changed into flat mechanism. The schematic diagrams of failure pattern for BM and WJ specimens are shown in Table 5. Table 5 represents a more damaging effect of differentiation in material property on life reduction, on the base information of the surface of failed samples that the crack source (CS) for the BM is located at one point of specimen surface; conversely, the crack initiation for WJ specimens emerged from multiple points on the specimen surface.

In this investigation, the continuous cycling tested specimens were examined using SEM (Hitach JEOL JSM 5610) to provide a great illustration of crack initiation and propagation. The fracture surfaces of crack initiation and propagation of Alloy 617 BM are revealed in Figure 10. SEM image of fracture surface for BM specimen shows the transgranular crack initiation (Figure 10(a)). Figure 10(b) shows, in the near of crack initiation site, cleavage-like features that were also observed in any fracture surface along the crack propagation and pattern of fatigue striations could be seen in BMs. With the help of the cross section of OM photograph in Figure $10(\mathrm{c})$, the fatigue crack propagation site was essentially characterized by typical fatigue striations which were perpendicular to the fatigue loading direction. The grain boundary sliding is restricted and the plastic cyclic strain provided by transgranular cracking. The transgranular cracking is more obvious in the BM specimens owing to its material properties. Eventually, the characteristics of BM are uniform and stable which caused the increasing of the fatigue crack resistance and resulted in a longer fatigue life.

Figure 11 shows typical fractograph for WJ specimen that experienced a transgranular crack initiation and propagation. 


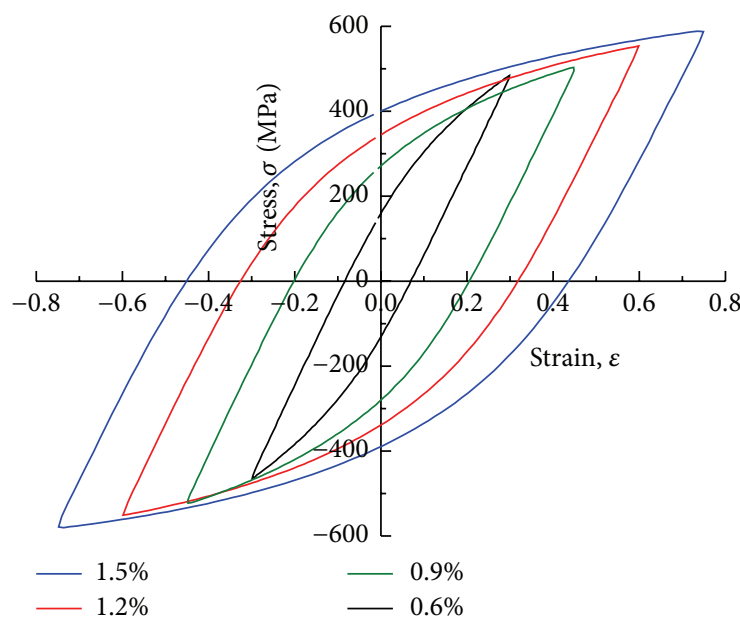

(a)

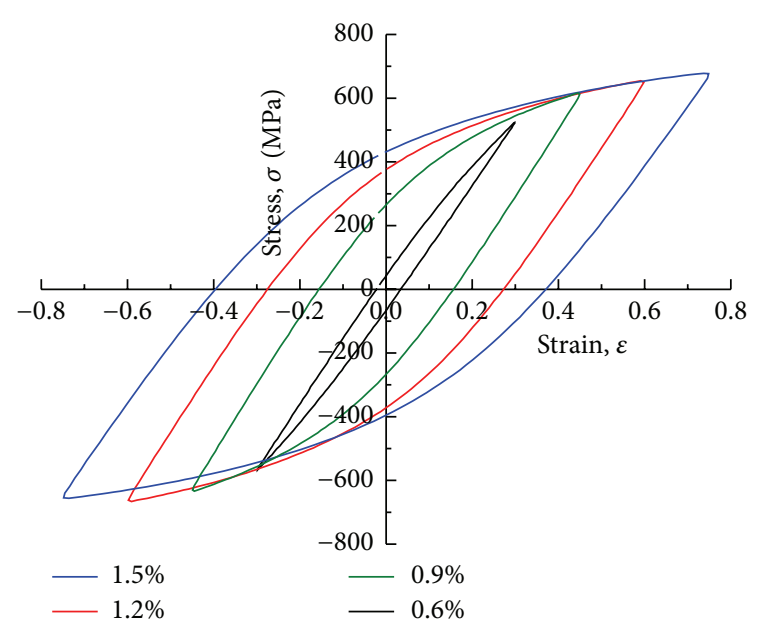

(b)

FIGURE 7: Stable hysteresis loops for a half-life at each total strain range for (a) Alloy 617 BM and (b) Alloy 617 WJ.

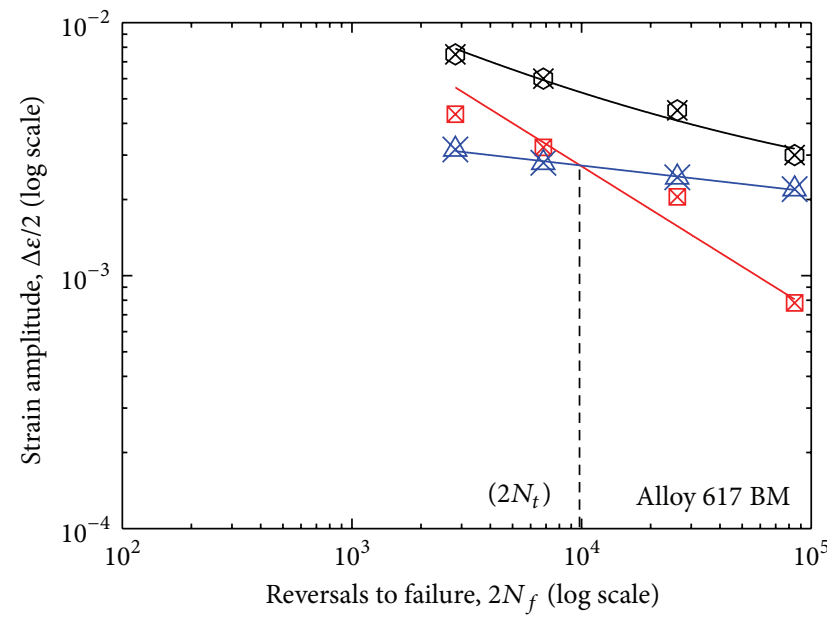

$\otimes$ Plastic strain

Elastic strain

Total strain

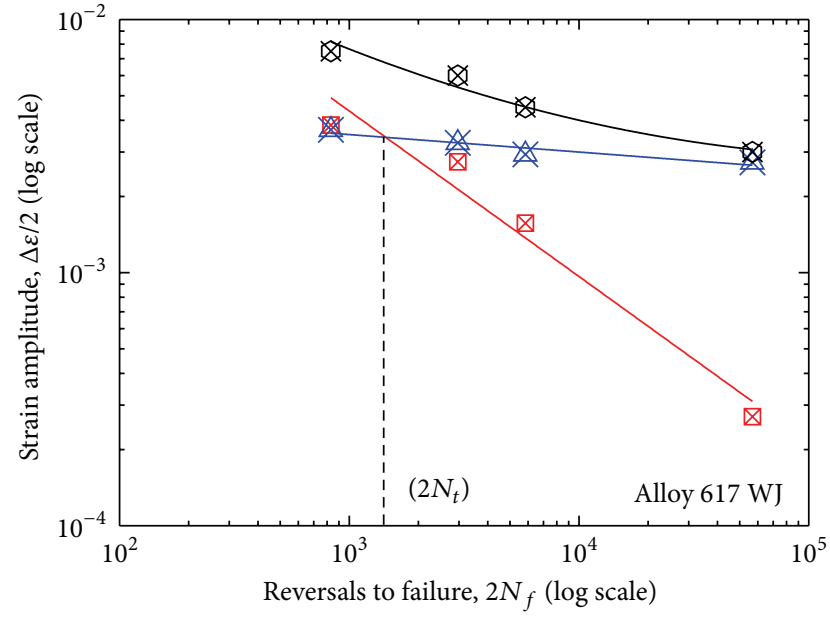

$\otimes$ Plastic strain

Elastic strain

Total strain

(a)

(b)

Figure 8: Coffin-Manson equation plots of (a) the BM and (b) the WJ.

Figure 11(a) shows SEM fractograph of several points on initiation site. However, the crack propagation stage was not significantly different than BM despite the dissimilarity in microstructure. The propagation mode for WJ appears to be sharper edges which followed dendritic paths and the fatigue striation was observed in the high magnification SEM image, shown in Figure 11(b). Shankar et al. reported for high strength materials [18] that the resistance to transgranular crack propagation in HAZ is less due to its coarse-grain size; that is, the smaller the grain boundary area, the less the number of crack-arrest events that causes the crack front to be held back and necessitates the crack initiation phase to occur in the adjacent grain. Somehow the fatigue life was less for WJs relative to those of BMs due to localized strain concentration in the HAZ region. Polák and Man [19] stated that the fatigue crack initiation in crystalline materials is related to the strain localization in the form of slip bands. This localized plastic strain results from dislocation mechanics which play an important role in the fatigue response of the material. The role of slip bands that contain extrusions and intrusions leads to the production of point defects that will develop into small cracks. At the beginning, the WJ may have original some defects in the microstructures [1] that could accelerate initiation for cracking during the service. Typical OM image of fracture surface in Figure 11(c) shows that the transgranular crack initiation of 45 degrees normal to the fatigue loading direction and failure occurred in the weld metal zone. It is interesting to note that such crack path deviations are obvious in this work. This could be associated with the heterogeneities which contribute to significant local 

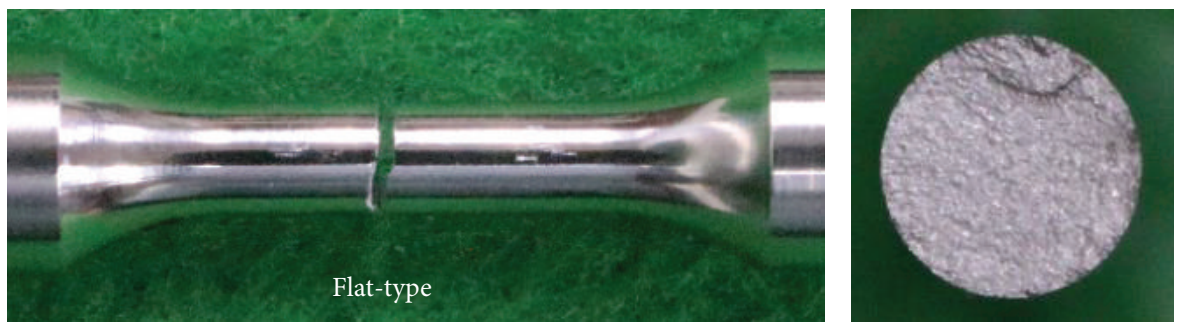

(a)
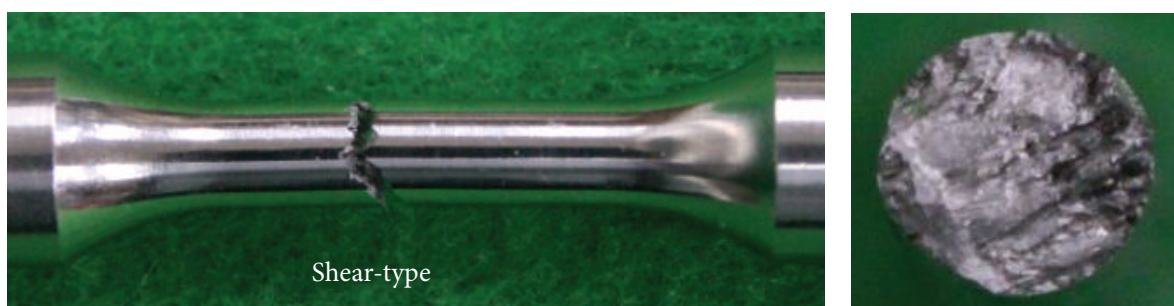

(b)

Figure 9: The fracture surface morphologies for (a) the BM and (b) WJ tested under total strain range, $0.6 \%$ condition.

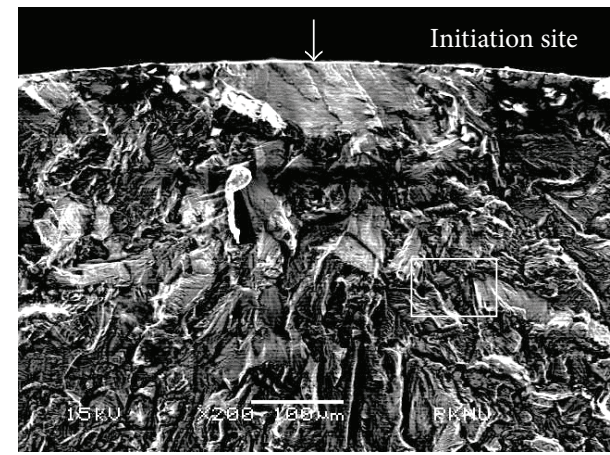

(a)

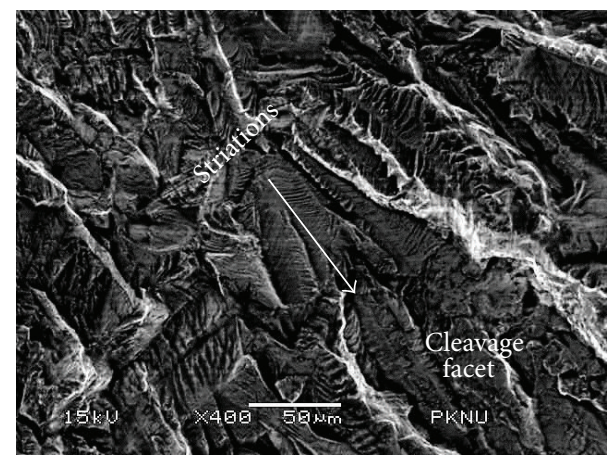

(b)

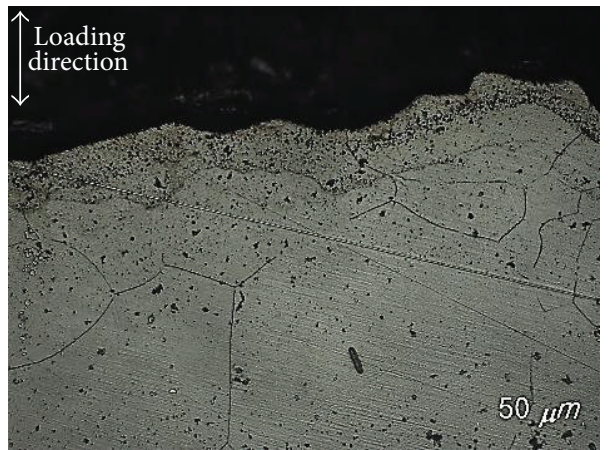

(c)

FIGURE 10: (a) SEM images representing a crack initiation site; (b) typical propagation SEM image showing fatigue striations; and (c) crosssectional OM image of surfaces for Alloy $617 \mathrm{BM}$ tested at $0.6 \%$ total strain range.

variations in the crack propagation at WJ specimens and also the coarse grain size in the weld metal zone and agree with the findings of previous work on Alloy 617 weldments [10]. Previously, Kim et al. [1] investigated the measurement of hardness for Alloy 617 welded joints; it showed that the weld zone showed a sharp increase compared to the BM and WM region because it was affected by thermal generated during the welding process. In particular pay attention to the fact that the possible weakness of the WM as well as the presence of microstructural heterogeneity, including the coarse grain size, can cause a reduction in fatigue resistance.

Figure 12 shows typical SEM fractographs of failed specimens tested at $1.5 \%$ total strain range for $\mathrm{BM}$ and $\mathrm{WJ}$ specimens. The failure region is larger at higher strain 


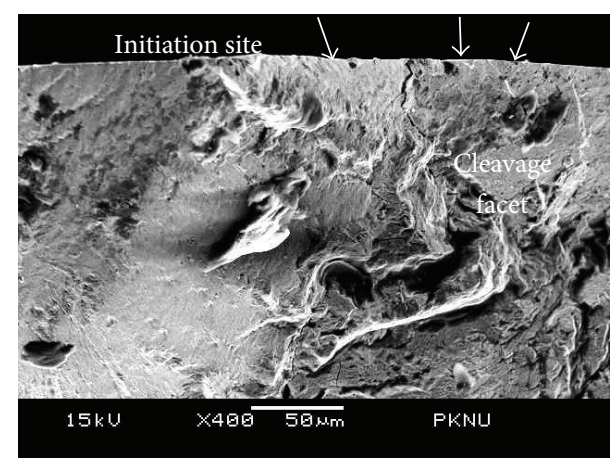

(a)

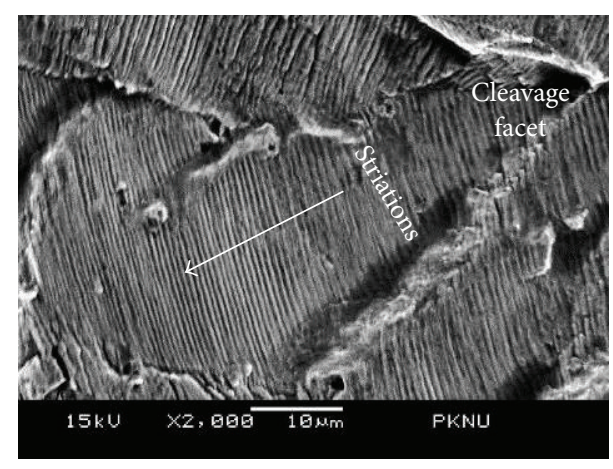

(b)

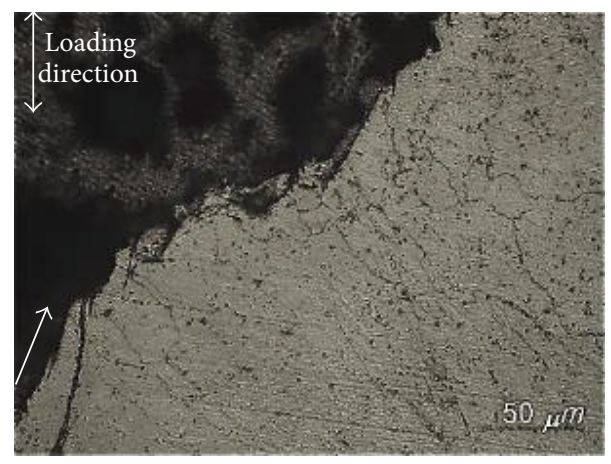

(c)

FIGURE 11: (a) SEM fractograph; (b) the crack propagation stage; (c) OM view of the fracture surfaces for Alloy 617 WJ tested at $0.6 \%$ total strain range.

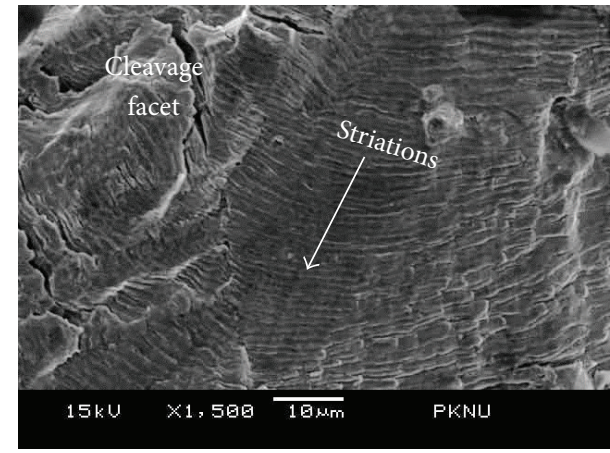

(a)

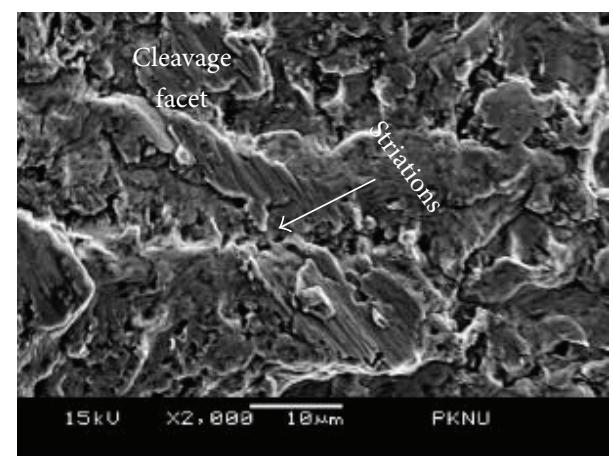

(c)

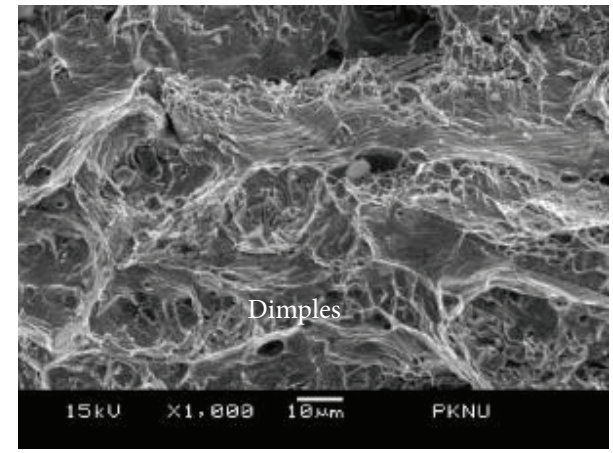

(b)

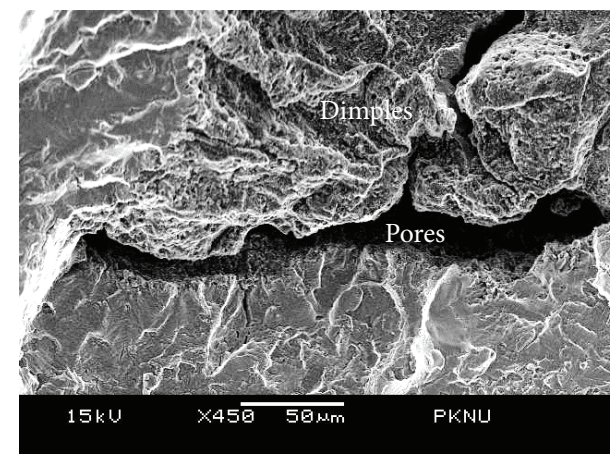

(d)

FIGURE 12: SEM images of the fractograph representing a crack propagation for low and high magnifications for ((a), (b)) Alloy 617 BM and ((c), (d)) Alloy $617 \mathrm{WJ}$, tested at 1.5\% total strain range, respectively. 

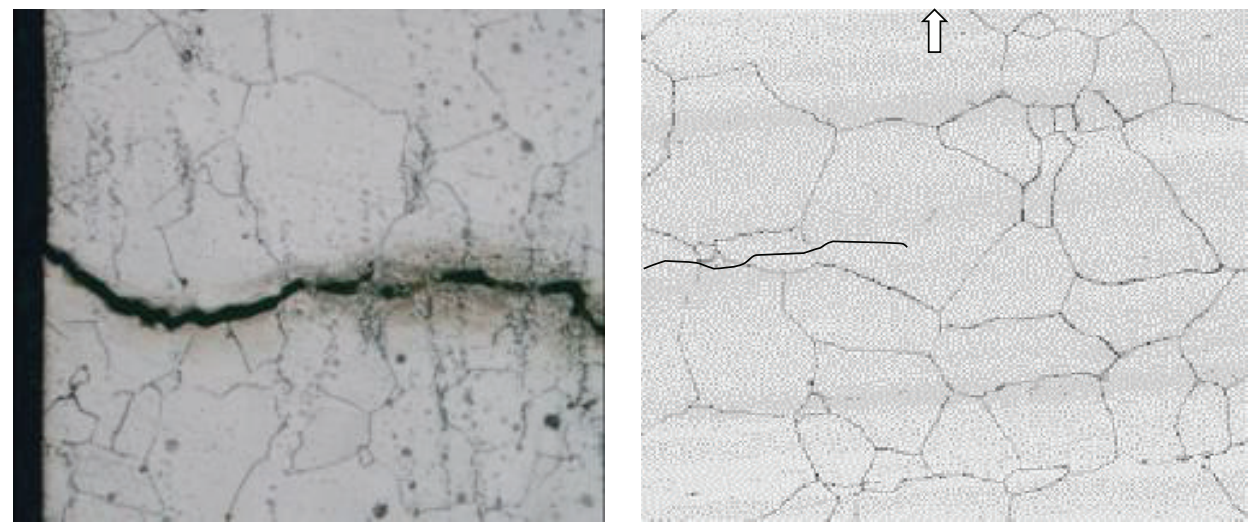

(a)
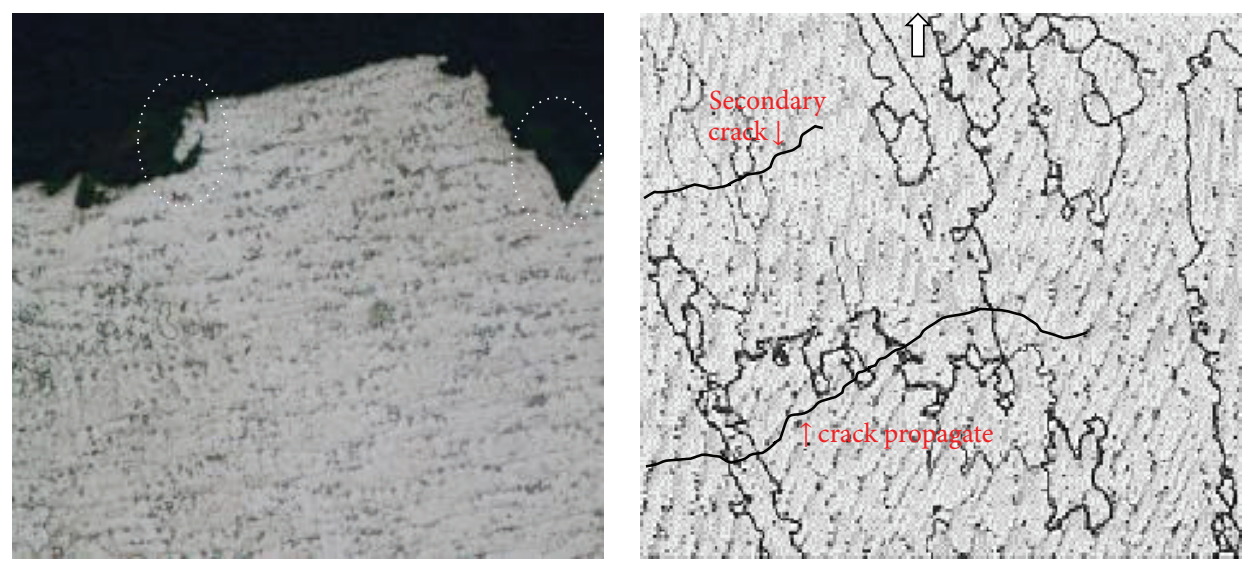

(b)

FIGURE 13: Schematic illustrations of the failure mechanism in pure fatigue representing a transgranular crack initiation and propagation along the fracture surfaces for (a) Alloy $617 \mathrm{BM}$ and (b) Alloy $617 \mathrm{WJ}$, tested at 1.5\% total strain range, RT.

range and somehow the propagation stage looks different. In Figures 12(a) and 12(c), the propagation area of samples tested at a higher strain amplitude of $1.5 \%$ had a smaller propagation area in both BM and WJ, compared with the samples tested at a lower strain amplitude of $0.6 \%$ (Figures 10 and 11), due to the higher cyclic stress response. The spacing of well-developed striations was also observed to be larger with increase in total strain range. However, at higher strain range, the fatigue striations will not be seen clearly in WJ due to reduction in crack propagation rate and fatigue life. Figures 12(b) and 12(d) show the propagation stage that was taken at higher magnification for BM and WJ, respectively. The fact that the WJ represents more obvious sharp edges and cleavage facets followed dendritic paths with several pores located at higher strain range. However, fracture surfaces show dimple ruptures due to the occurrence of microvoids in the failure region for $\mathrm{BM}$ and $\mathrm{WJ}$ tested at $1.5 \%$ total strain range. Furthermore, the size of the crack propagation area was mainly associated with the applied strain amplitude in both BMs and WJ specimens. The higher the applied total strain range was, the smaller the propagation area was.

The LCF failure mode outlined above has been presented in advance at room temperature and selected total strain condition. The mode is schematically illustrated and compared to micrographs of Alloy 617 crack paths in Figure 13.
It should be noted that the secondary cracks or the fracture surface could describe the mode of failure of this alloy under these specific conditions. The fatigue crack initiation and propagation are dominated by the crack that traveled cut along the grain boundaries, and it is relative to the pure fatigue phenomena. In the current work, testing condition such as temperature did not contribute well to this mechanism result, despite being at all investigated total strain ranges. The premature of crack propagation which manifests deviations in WJs (Figure 13(b)) which were expected from the presence of microstructural heterogeneity includes the dendritic structure.

Future work for high temperature LCF testing is planned specifically on all WJ specimens to distinguish the fatigue behavior of Alloy 617 welded joints by GTAW process.

\section{Conclusions}

The strain-controlled LCF testing of Alloy 617 base metal and Alloy 617 the welded joints was performed at four different total strain ranges, $0.6,0.9,1.2$, and $1.5 \%$ at room temperature in air conditions. The cyclic stress response for both $\mathrm{BM}$ and WJ specimens exhibited a cyclic softening regime for the major portion of the fatigue life after a brief period of initial hardening. The short period of cyclic initial hardening 
was observed about $2-200$ cycles for both BM and WJ specimens and remained softening phase until failure. The WJ specimens have shown a higher cyclic stress response than the BM specimens. Contrarily, the BM showed a higher value of degree of initial hardening, $H_{s}$, compared to WJ. Furthermore, the material constants have been evaluated and characterized by the Coffin-Manson relationship. The great results appeared and can be well compared with the experimental data.

Fatigue resistance was decreased with increasing the total strain ranges; thereafter the fatigue lives of $\mathrm{WJ}$ specimens were reduced relative to those of BM specimens. The low cycle fatigue crack initiation and propagation occurred in transgranular mode for BM and WJ specimens in this work. Furthermore, the fracture behavior of the BM is very flat related to the fatigue loading axis, whereas that of the $\mathrm{WJ}$ is relatively wedge-type (star/shear shape) and consequently transgranular cracking initiation is 45 degrees normal to the fatigue loading axis. Cracks in WJ specimens initiated in weld metal region.

\section{Conflict of Interests}

The authors declare that there is no conflict of interests regarding the publication of this paper.

\section{Acknowledgment}

This research was supported by Nuclear Research \& Development Program through the National Research Foundation of Korea (NRF) funded by the Ministry of Science, ICT \& Future Planning (NRF-2014M2A8A2020785).

\section{References}

[1] W.-G. Kim, J.-Y. Park, I. M. W. Ekaputra, S.-D. Hong, S.-J. Kim, and Y.-W. Kim, "Comparative study on the high-temperature tensile and creep properties of Alloy 617 base and weld metals," Journal of Mechanical Science and Technology, vol. 27, no. 8, pp. 2331-2340, 2013.

[2] S. J. Kim, P. H. Choi, R. T. Dewa, W. G. Kim, and M. H. Kim, "Low cycle fatigue properties of Alloy 617 base metal and weld joint at Room Temperature," Procedia Materials Science, vol. 3, pp. 2201-2206, 2014.

[3] J. P. Strizak, C. R. Brinkman, and P. L. Rittenhouse, "High temperature low-cycle fatigue and tensile properties of Hastelloy X and alloy 617 in air and HTGR-helium," in Proceedings of the IAEA Specialists' Meeting on 'High Temperature Metallic Materials for Application in Gas Cooled Reactors', Oak Ridge National Laboratory, Vienna, Austria, May 1981.

[4] H. Nickel, F. Schubert, and H. Schuster, "Evaluation of alloys for advanced high-temperature reactor systems," Nuclear Engineering and Design, vol. 78, no. 2, pp. 251-265, 1984.

[5] L. J. Carroll, C. Cabet, M. C. Carroll, and R. N. Wright, "The development of microstructural damage during high temperature creep-fatigue of a nickel alloy," International Journal of Fatigue, vol. 47, pp. 115-125, 2013.

[6] X. Chen, Z. Yang, M. A. Sokolov, D. L. Erdman III, K. Mo, and J. F. Stubbins, "Effect of creep and oxidation on reduced fatigue life of Ni-based alloy 617 at $850^{\circ}$ c," Journal of Nuclear Materials, vol. 444, no. 1-3, pp. 393-403, 2014.

[7] T. C. Totemeier and H. Tian, "Creep-fatigue interactions in INCONEL 617," Materials Science and Engineering A, vol. 468470, pp. 81-87, 2007.

[8] K. B. S. Rao, H. Schiffers, H. Schuster, and H. Nickel, "Influence of time and temperature dependent processes on strain controlled low cycle fatigue behavior of alloy 617," Metallurgical Transactions A, vol. 19, no. 2, pp. 359-371, 1988.

[9] M. A. Burke and C. G. Beck, "The high temperature low cycle fatigue behavior of the nickel base Alloy IN-617," Metallurgical Transactions. A, vol. 15, no. 4, pp. 661-670, 1984.

[10] T. C. Totemeier, "High-temperature creep-fatigue of alloy 617 base metaland weldments," in Proceedings of the 8th International Conference on Creep and Fatigue at Elevated Temperatures, ASME Pressure Vessels and Piping Conference, vol. 9, pp. 255-260, July 2007.

[11] G. V. P. Reddy, R. Sandhya, M. Valsan, and K. B. S. Rao, "High temperature low cycle fatigue properties of $316(\mathrm{~N})$ weld metal and $316 \mathrm{~L}(\mathrm{~N}) / 316(\mathrm{~N})$ weld joints," International Journal of Fatigue, vol. 30, no. 3, pp. 538-546, 2008.

[12] ASTM International, "ASTM E 606-92, standard practice for strain-controlled fatigue testing," in Annual Book of ASTM Standards, vol. 03.01, p. 569, ASTM International, Baltimore, Md, USA, 2002.

[13] ASTM International, Standard Specification for Nickel-Chromium-Iron Alloys (UNS N06600, N06601, N06603, N06690, N06693, N06025, N06045, and N06696) and Nickel-Chromium Cobalt Molybdenum Alloy (UNS N06617) Plate, Sheet, and Strip, ASTM International, West Conshohocken, Pa, USA, 2008.

[14] O. Fatoba and R. Akid, "Low cycle fatigue behaviour of API 5L X65 pipeline steel at room temperature," Procedia Engineering, vol. 74, pp. 279-286, 2014.

[15] J. K. Wright, L. J. Carroll, J. A. Simpson, and R. N. Wright, "Low cycle fatigue of alloy 617 at $850^{\circ} \mathrm{C}$ and $950^{\circ} \mathrm{c}$," Transactions of the ASME-Journal of Engineering Materials and Technology, vol. 135, no. 3, Article ID 031005, 8 pages, 2013.

[16] K. B. S. Rao, H. Schuster, and G. R. Halford, "Mechanisms of high-temperature fatigue failure in alloy $800 \mathrm{H}$," Metallurgical and Materials Transactions A: Physical Metallurgy and Materials Science, vol. 27, no. 4, pp. 851-861, 1996.

[17] J. Kang, F. C. Zhang, X. Y. Long, and B. Lv, "Cyclic deformation and fatigue behaviors of Hadfield manganese steel," Materials Science and Engineering A, vol. 591, pp. 59-68, 2014.

[18] V. Shankar, M. Valsan, K. B. S. Rao, and S. D. Pathak, "Low cycle fatigue and creep-fatigue interaction behavior of modified 9Cr1 Mo ferritic steel and its weld joint," Transactions of the Indian Institute of Metals, vol. 63, no. 2-3, pp. 622-628, 2010.

[19] J. Polák and J. Man, "Fatigue crack initiation-the role of point defects," International Journal of Fatigue, vol. 65, pp. 18-27, 2014. 

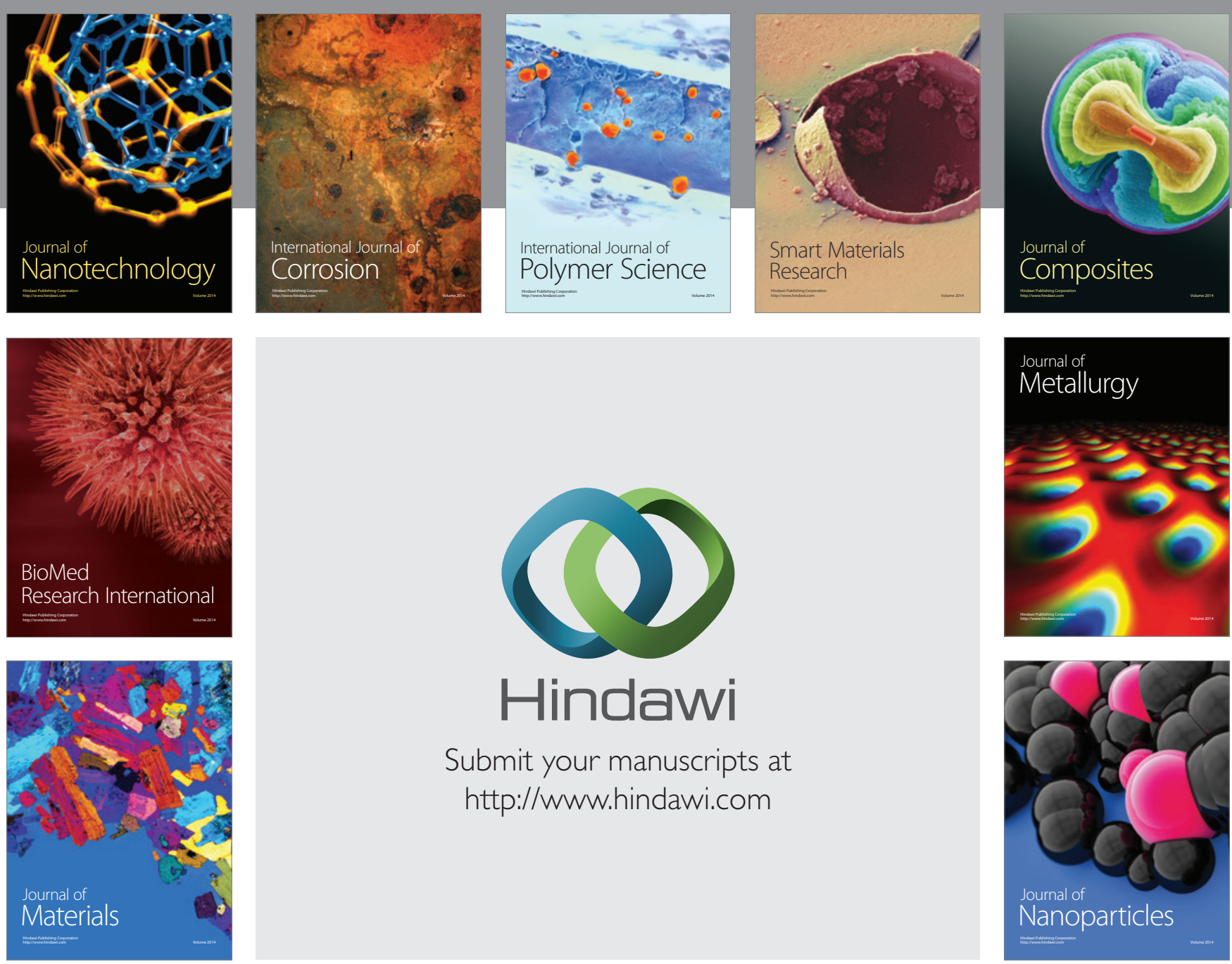

Submit your manuscripts at http://www.hindawi.com
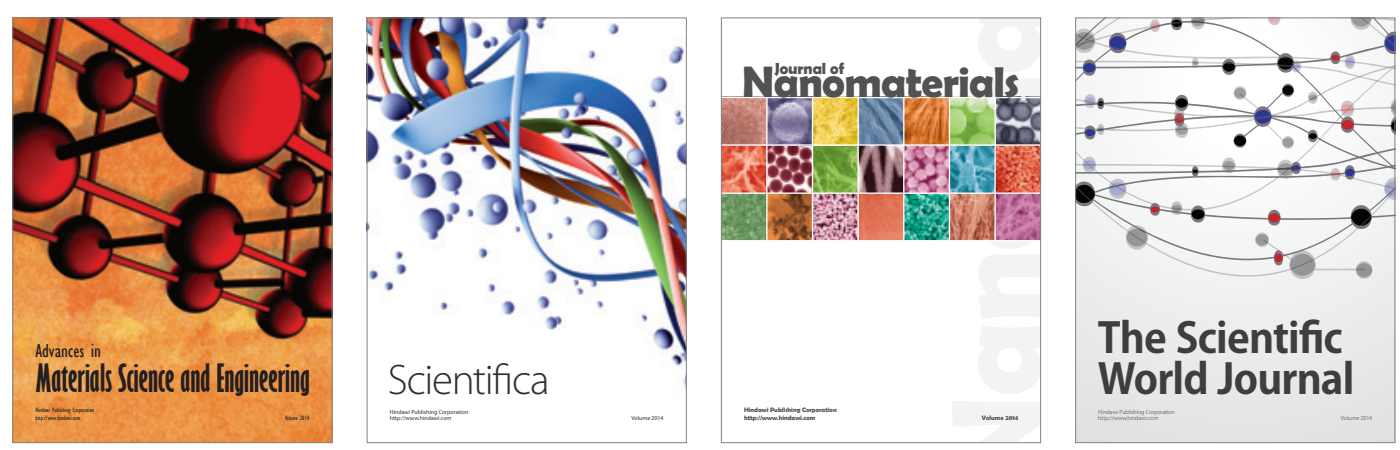

\section{The Scientific World Journal}
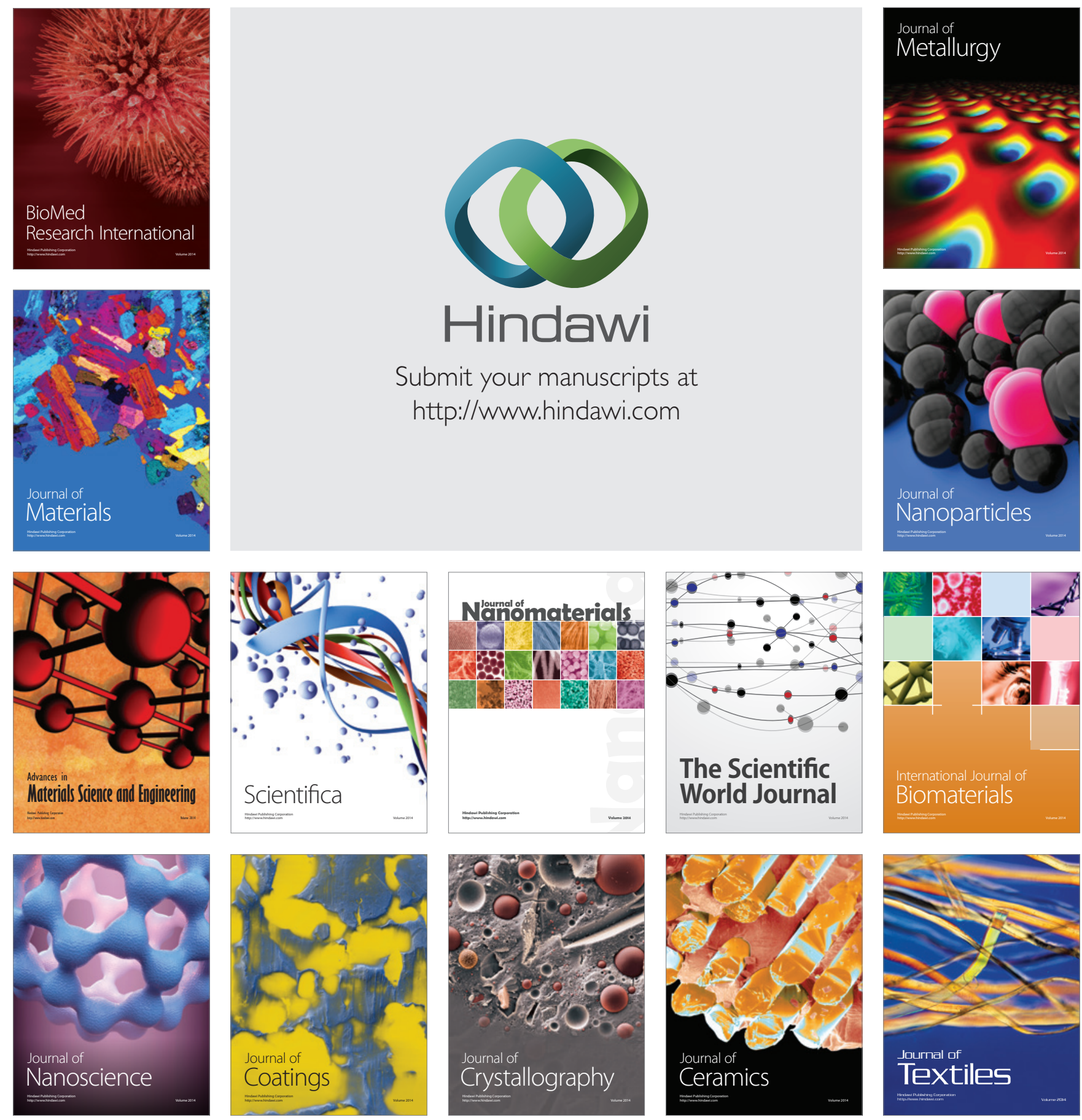